Check for updates

Cite this: Chem. Commun., 2020, 56, 13540

Received 9th September 2020 Accepted 2nd October 2020

DOI: $10.1039 / \mathrm{d} 0 \mathrm{cc} 06093 \mathrm{c}$

rsc.li/chemcomm

\section{Experimental validation of pressure swing regeneration for faster cycling in sorption enhanced dimethyl ether synthesis $\dagger$}

\author{
Jasper van Kampen, (D) *ab Saskia Booneveld, ${ }^{a}$ Jurriaan Boon, (D) ${ }^{\text {ab }}$ Jaap Vente ${ }^{\mathrm{a}}$ and \\ Martin van Sint Annaland (iD ${ }^{b}$
}

Sorption enhanced dimethyl ether synthesis (SEDMES) is a novel DME production route from $\mathrm{CO}_{2}$-rich feedstocks. In situ water removal by adsorption results in high single-pass conversions, thereby circumventing the disadvantages of conventional routes, such as low carbon efficiency, energy intensive downstream separation and large recycling. The first-time demonstration of pressure swing regeneration with $\mathbf{8 0} \%$ single-pass carbon selectivity to DME allows for an enormous increase in productivity. Already a factor four increase compared to temperature swing regeneration is achieved, unlocking the potential of SEDMES as a carbon utilisation technology.

Dimethyl ether (DME) is a valuable platform chemical and synthetic fuel. It is expected to play an important role in the current energy transition, where fossil-based fuels and chemicals have to be replaced by products from renewable feedstocks. ${ }^{1-3}$ This is envisioned by the chemical recycling of carbon dioxide directly, ${ }^{4}$ as well as by indirect conversion via biomass-based, $\mathrm{CO}_{2}$-rich syngas. However, the production of DME from a $\mathrm{CO}_{2}$-rich feedstock or $\mathrm{CO}_{2}$ directly via conventional processes is limited and therefore considered unattractive. ${ }^{5,6}$ Similar to many other industrial $\mathrm{CO}_{2}$ utilisation processes, the main hurdle is the production and efficient handling of steam. ${ }^{4,7,8}$ Steam separation enhancement is a promising route for $\mathrm{CO}_{2}$ utilisation. ${ }^{7}$ The concept of separation enhancement is based on Le Chatelier's principle, according to which an equilibrium limited reaction is shifted to enhance conversion by selectively removing reaction products, and is mainly utilised for various processes and products considering $\mathrm{CO}_{2}$ separation. ${ }^{9,10}$ Sorption enhanced DME synthesis (SEDMES),

\footnotetext{
${ }^{a}$ Biomass and Energy Efficiency, TNO Energy Transition, P. O. Box 15, 1755 ZG Petten, The Netherlands. E-mail: jasper.vankampen@tno.nl

${ }^{b}$ Chemical Process Intensification, TU/e, P. O. Box 513, 5600 MB Eindhoven, The Netherlands. E-mail: j.v.kampen@tue.nl

$\dagger$ Electronic supplementary information (ESI) available. See DOI: 10.1039/ d0cc06093c
}

which combines direct DME synthesis with in situ water removal using a solid adsorbent, is a promising process intensification for the direct production of DME from $\mathrm{CO}_{2}{ }^{7,11-13}$ While enabling increased single-pass conversion and selectivity, experimental studies have indicated that time and energy intensive temperature swing regeneration would be required for adsorbent regeneration. ${ }^{7,13}$ A potentially faster and more energy efficient approach is pressure swing regeneration as recently indicated in a SEDMES modelling study. ${ }^{13}$ The current communication reports the results of an experimental investigation on the bench-scale sorption enhanced production of DME. Special attention is being paid to the mode of regeneration, as the key to an economically attractive process.

Sorption enhanced DME synthesis is validated experimentally using a 2 litre bench-scale reactor, details of which are provided in the ESI. $\dagger$ Fig. 1 shows a representative breakthrough experiment of sorption enhanced DME synthesis.

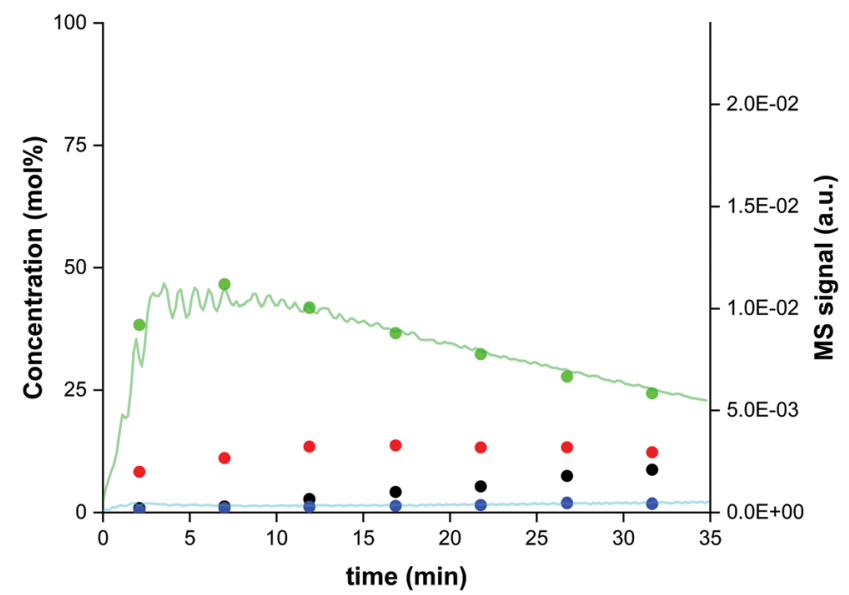

Fig. 1 Experimental data at $250{ }^{\circ} \mathrm{C}$ and 25 bar for a $\mathrm{CO}_{2}: \mathrm{CO}=2: 1$ feed with stoichiometric hydrogen. GC data (dots: DME (green), $\mathrm{CO}$ (red), $\mathrm{CO}_{2}$ (black), and methanol (blue)) and MS breakthrough profile for DME (green line) and $\mathrm{H}_{2} \mathrm{O}$ (light blue line). 


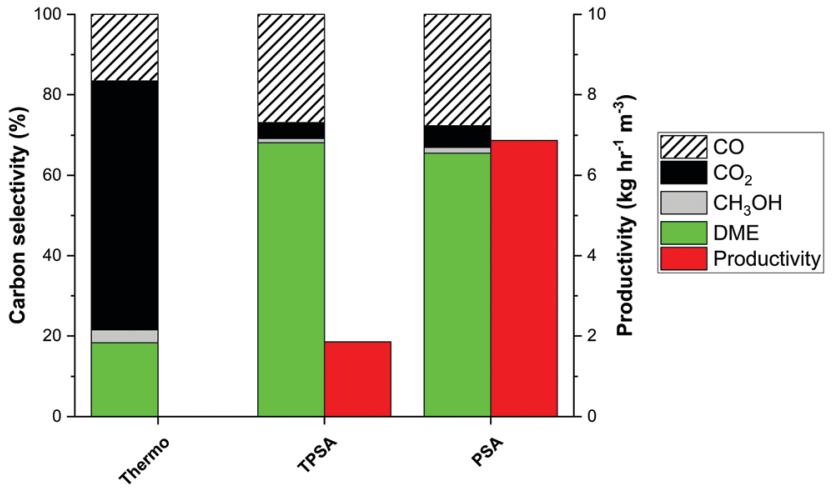

Fig. 2 Thermodynamic (maximally possible) carbon distribution without sorption enhancement versus experimentally obtained TPSA and PSA results for sorption enhanced DME synthesis. Conditions: $275{ }^{\circ} \mathrm{C}$ and 25 bar for a $\mathrm{CO}_{2}: \mathrm{CO}=2: 1$ feed with stoichiometric hydrogen and $\mathrm{CH}_{4}$ tracer. TPSA: regeneration included heating up to $400{ }^{\circ} \mathrm{C}$.

$\mathrm{CO}_{2}$-rich syngas $\left(\mathrm{CO}_{2}: \mathrm{CO}=2: 1\right.$, stoichiometric $\left.\mathrm{H}_{2}\right)$, as typical for biomass-derived syngas, is fed to a previously regenerated column, at $250-275{ }^{\circ} \mathrm{C}$ and 25 bar, containing a homogeneous mixture of a CuZnAl catalyst, a $\gamma-\mathrm{Al}_{2} \mathrm{O}_{3}$ catalyst, and a $3 \mathrm{~A}$ zeolite adsorbent, all of which are commercially available. The reactor outlet composition is measured using mass spectrometry and gas chromatography, as shown in Fig. 1. Prior to steam breakthrough, DME and unconverted CO are the primary products. After steam breakthrough, the concentration of DME drops, accompanied by the breakthrough of $\mathrm{CO}_{2}$ and methanol, indicating saturation of the adsorbent. These bench-scale test results demonstrate high performance with over $80 \%$ integral carbon selectivity towards DME when using pressure swing regeneration, without the need for a temperature swing, for the first time in the open literature. In Fig. 2 the experimental carbon distribution for SEDMES at $275{ }^{\circ} \mathrm{C}$ is shown, indicating the single-pass conversion increase from $18 \%$ for conventional synthesis (represented as the thermodynamic equilibrium) to $68 \%$. Crucially, the experiment serves to show how a similar

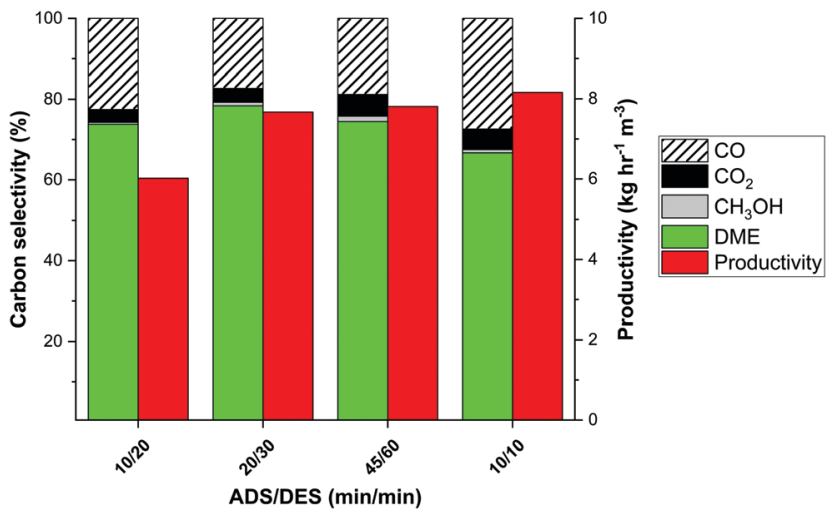

Fig. 3 Carbon selectivity and the productivity for the current number of columns (adsorption + purge time; red bars) as a function of ADS/DES ratio; integration until $5 \% \mathrm{CO}_{2}$ breakthrough. Conditions: $250{ }^{\circ} \mathrm{C}$ and 25 bar for a $\mathrm{CO}_{2}: \mathrm{CO}=2: 1$ feed with stoichiometric hydrogen and $\mathrm{CH}_{4}$ tracer. conversion and selectivity can be obtained with pressure swing regeneration (PSA) in comparison with previously reported experiments with a combined temperature and pressure swing regeneration (TPSA). As no time is required for heating and cooling, the adsorbent regeneration time can be reduced from 360 minutes to 60 minutes under the current conditions (Fig. 2). As a result, the DME productivity is already increased by a factor of four, with further optimisation possible.

Following the proof of feasibility of pressure swing regeneration, the cycle design of the sorption enhanced process becomes essential. The combination of the adsorption duration (ADS) and regeneration time (DES) allows optimising the tradeoff for DME selectivity and productivity, which is shown in Fig. 3. Shorter adsorption times potentially result in an increased production rate. The larger reactor column requirement $\left(\mathrm{m}^{3}\right)$ when the purge time does not decrease with the adsorption time, however, results in a drop in cyclic productivity $\left(\mathrm{kg} \mathrm{h} \mathrm{h}^{-1} \mathrm{~m}^{-3}\right)$. Considering the minimum number of columns required for any given adsorption and purge time, the productivity could be significantly boosted for shorter cycle times with the highest ADS/DES ratio (red bars in Fig. 3). The productivities reported in Fig. 3 correspond to 0.04-0.06 $\mathrm{kg} \mathrm{h}^{-1} \mathrm{~kg}_{\text {cat }}{ }^{-1}$. This is a major improvement compared to the previously reported TPSA cycle and close to direct DME pilot plant productivity for CO to DME, which would strongly deteriorate for $\mathrm{CO}_{2}$-rich feed. ${ }^{13}$

This increase in productivity shows the impact of the demonstrated PSA regeneration on the SEDMES process performance. Benefiting from this work, optimisation of the cycle design by means of modelling and experimental validation should further unlock the potential of SEDMES as an efficient carbon utilisation technology. Followed by the technoeconomic and life cycle analyses, the economic and carbon mitigating benefits of SEDMES over conventional DME synthesis technology can also now be addressed.

This work has received funding from the European Union's Horizon 2020 Research and Innovation Programme under grant agreement no. 727600 .

\section{Conflicts of interest}

There are no conflicts to declare.

\section{References}

1 T. A. Semelsberger, R. L. Borup and H. L. Greene, Dimethyl ether (DME) as an alternative fuel, J. Power Sources, 2006, 156, 497-511.

2 C. Arcoumanis, C. Bae, R. Crookes and E. Kinoshita, The potential of di-methyl ether (DME) as an alternative fuel for compressionignition engines: a review, Fuel, 2008, 87, 1014-1030.

3 G. A. Olah, A. Goeppert and G. K. S. Prakash, Chemical Recycling of Carbon Dioxide to Methanol and Dimethyl Ether, J. Org. Chem., 2009, 74, 487-498.

4 G. Centi and S. Perathoner, Opportunities and prospects in the chemical recycling of carbon dioxide to fuels, Catal. Today, 2009, 148, 191-205.

5 V. Dieterich, A. Buttler, A. Hanel, H. Spliethoff and S. Fendt, Powerto-liquid via synthesis of methanol, DME or Fischer-Tropsch-fuels: a review, Energy Environ. Sci., 2020, DOI: 10.1039/d0ee01187h. 
6 R. J. Detz, J. N. H. Reek and B. C. C. van der Zwaan, The future of solar fuels: when could they become competitive?, Energy Environ. Sci., 2018, 11, 1653-1669.

7 J. van Kampen, J. Boon, F. van Berkel, J. Vente and M. van Sint Annaland, Steam separation enhanced reactions: Review and outlook, Chem. Eng. J., 2019, 374, 1286-1303.

8 A. Katelhon, R. Meys, S. Deutz, S. Suh and A. Bardow, Climate change mitigation potential of carbon capture and utilization in the chemical industry, Proc. Natl. Acad. Sci. U. S. A., 2019, 116, 11187-11194.

9 A. E. Rodrigues, L. M. Madeira, Y.-J. Wu and R. Faria, Sorption Enhanced Reaction Processes, Sustainable Chemistry Series, World Scientific, 2017, vol. 1, DOI: 10.1142/q0103.

10 J. C. Abanades, J. Boon, P. Cobden, K. Coenen, D. S. M. Constantino, R. P. V. Faria, J. R. Fernández, F. Gallucci, M. C. Iliuta,
A. E. Rodrigues, E. van Dijk and M. van Sint Annaland, Sorption Enhancement of Chemical Processes, Academic Press, 1st edn, 2017.

11 I. Iliuta, M. C. Iliuta and F. Larachi, Sorption-enhanced dimethyl ether synthesis-multiscale reactor modeling, Chem. Eng. Sci., 2011, 66, 2241-2251.

12 J. Boon, J. van Kampen, R. Hoogendoorn, S. Tanase, F. P. F. van Berkel and M. van Sint Annaland, Reversible deactivation of $\gamma$ alumina by steam in the gas-phase dehydration of methanol to dimethyl ether, Catal. Commun., 2019, 119, 22-27.

13 J. van Kampen, J. Boon, J. Vente and M. van Sint Annaland, Sorption enhanced dimethyl ether synthesis for high efficiency carbon conversion: modelling and cycle design, J. $\mathrm{CO}_{2}$ Util., 2020, 37, 295-308. 